\title{
Ulises I una misión de arte al espacio: Book Report
}

Un libro que narra una historia de la vida real por el Colectivo Espacial Mexicano.

Se presentó en la Feria Internacional del Libro de Guadalajara el 1 de diciembre del 2017 a las 13 horas.Se distribuye como un performance de manera gratuita en su versión de Ipad

En inglés y en español http://csi.asu.edu/books/ulises/

"El futuro pertenece a aquellos que

brindan a la siguiente generación una

razón de esperanza"

Teilhard de Chardin

La misión al espacio de Ulises I nace en el año 2010 como una reacción de autodefensa hacia la situación de guerra e inseguridad que se experimentaba en México, en esas fechas se contaban 50 mil muertos.

Ulises I se planteó en esencia una necesidad de cambiar la realidad, es decir, recuperar la capacidad de crear nuevas metáforas. Había que diseñar una acción imposible y llevarla a cabo. Ulises I es el nombre de un pequeño satélite obra de arte. La idea, una misión al espacio, como ciudadanos, como artistas, como habitantes del mundo, establecer una prueba contundente de que se puede cambiar la realidad. Urge la inteligencia, la imaginación, las nuevas metáforas, la poesía en su definición original de llevar las ideas a la materia.

Misión: construir un satélite experimental para cambiar la realidad

Misión científica: nuevo discurso para un científico mexicano

Misión de arte: progresión poética, un proceso de arte y ciencia

Misión para el plano social: ciudadanización de la ciencia

Misión política: invitación a instituciones, facilitar la sinergia de gestión

Satélite tipo: Nanosatélite tipo Tubesat

Objetivo: satélite en órbita polar a $300 \mathrm{kms}$ altura

Transmitiendo: $436.5 \mathrm{Mghz}$

Carga útil: obra electrónica, poética y sonora de varios artistas

Lanzamiento contratado: Interorbital Systems

Status de la misión: listo para lanzamiento, certificación completa, permiso SCT

Diseño de la misión : Colectivo Espacial Mexicano

Colaboración técnica con el INAOE y Centro Multimedia 
En un miércoles cualquiera lo más dificil que se puede proponer un equipo o una persona en el mundo es generar "otra carrera espacial", armando un satélite que además es una obra de arte y hacerlo sólo por razones poéticas en un país del tercer mundo.

La misión Ulises I generó el concepto de un Colectivo, el Colectivo Espacial Mexicano, un equipo como el autor de esta obra de arte. El Colectivo se fundó como grupo ciudadano en el 2010, un año antes de la fundación de la Agencia Espacial Mexicana. Nuestros preceptos y conceptos revolucionarios, diseñar la célula mínima para llegar al espacio, una metodología de construcción de metáforas como motores de creación de realidad, rediseño del concepto de trabajo en equipo, transferencia de tecnología, creación de tejido social, nuevos niveles de producción de ciencia.

Redefinición de procesos desde el arte como misión, oficio, concepto de profesional, saber soñar, la tecnología como manera de pensar, apropiación de la ciencia, saber ser equipo, cooperación en vez de competencia, una política espacial propia, uso correcto de la instituciones, provocar en más gente el efecto perspectiva.

Es una una reflexión de vernos, no solamente como mexicanos, sino como habitantes del planeta Tierra. Explorar la famosa frase de Neil Armstrong, "un pequeño paso para el hombre, un gran salto para la humanidad." Nosotros en México igual que una niña en Siria también somos la humanidad. La pregunta : cuál fue nuestro salto. Hoy el colectivo espacial mexicano quiere ir al espacio, como ciudadanos cualquiera y plantear si el espacio es realmente un fenómeno global.

El lanzamiento es el mensaje. El libro y diario de viaje de Ulises se ha diseñado con una arquitectura especial, es decir sus textos, fotografías, datos, planos, esconden unos códigos coherentes y al final, el libro también es una nave espacial como sugiere Emily Dickinson. Es una bitácora exacta como un diario de viaje, narra de manera detallada paso por paso quiénes intervienen, el intento de usar las instituciones en función del ciudadano. Ulises I significa más de lo que mide, su estatura son $12 \mathrm{cms}$ de altura que es la mitad de esta página que escribo, o la mitad de esta pantalla en que lo leo. El libro narra cómo durante 5 años se han diseñado 8 misiones de arte espaciales, 23 presentaciones nacionales e internacionales, 7 exposiciones de arte y ciencia y, se han certificado para lanzamiento al espacio dos satélites. Al leer el libro, se puede leer como un libro de artista, o para un poeta puede ser un libro de literatura fractal, para un lector de comics puede ser ciencia ficción, también esta extraña nave-libro es un objeto endosado por ITACCUS, el comité cultural de la Federación Astronáutica Internacional. Todos sus materiales fueron hechos de manera específica para esta publicación, su contenido es una síntesis extrema. La página 94 permite ver un video de 30 minutos que explica el proyecto también. La página 27 explica el color del universo por fuera, la 81 trae un retrato de un sámurai fuera de Japón, que vive en México, pero que redefine el sentido de ser un samurai en el siglo XXI y cómo se relaciona a una misión espacial. 


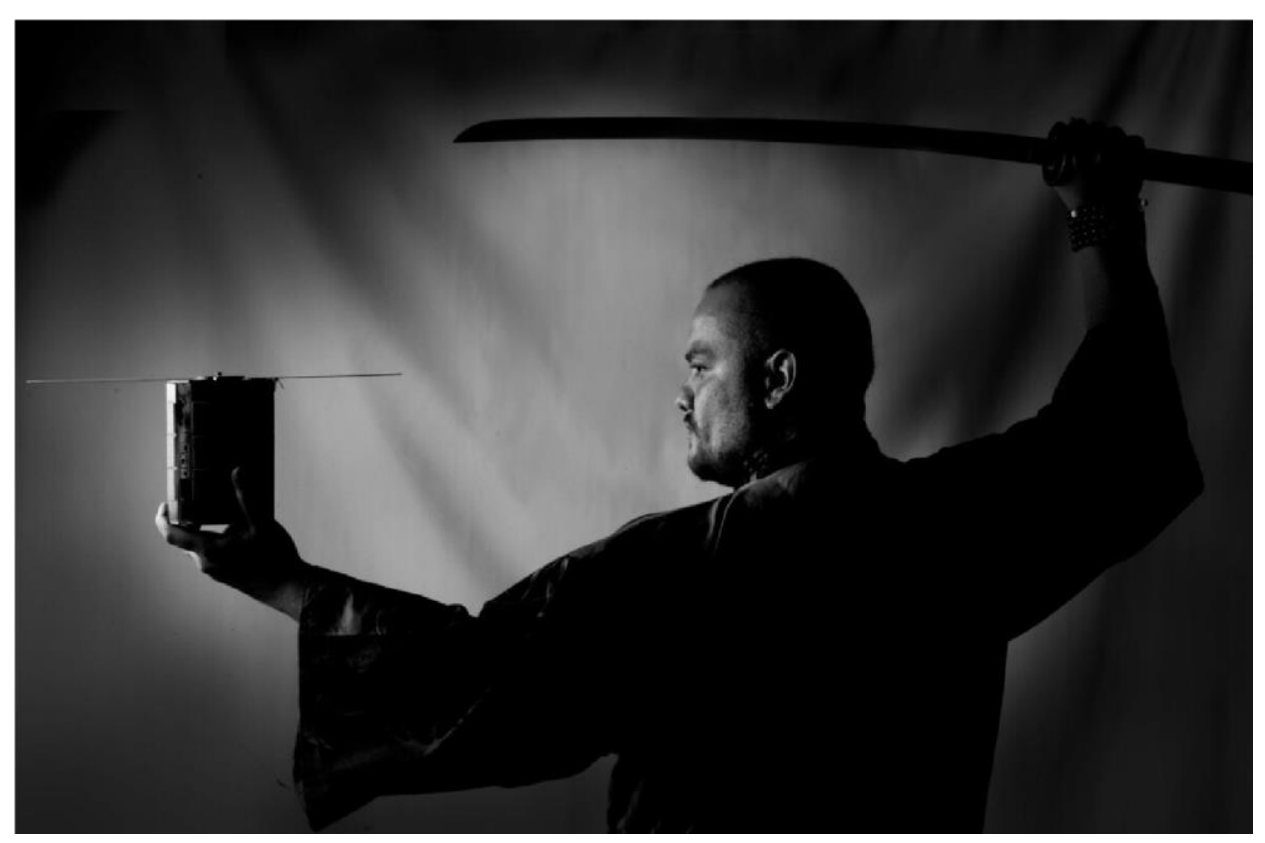

En las demás páginas se distribuyen huellas digitales, citas de Jaques Tati, planos, dibujos, bocetos, partituras, contratos, fotografías, emails, esquemas, citas, recortes de periódico, citas de otros libros, testimonios del equipo, direcciones de internet, un libro que tiene varias lecturas, hasta cómo hacer una misión, una narrativa de arte postconceptual. Ulises I tiene 4 textos centrales, Edward Finn, Fernando Castro, Omar Gasca y Antonio Lafuente. Textos que narran la aventura de distintos ángulos, Ed como director del Centro de Ciencia e Imaginación de Arizona State University habla de la necesidad de reconceptualizar el espacio. Fernando Castro escribió una síntesis de la aventura para un artículo de la revista Literal, Omar Gasca habla del verbo "jugar" y la falta de traducción de la palabra play al español y Antonio Lafuente escribe un texto sobre los amateurs. El Colectivo propone la metáfora prometida, un México y un mundo 2.0, un mundo que requiere de un upgrade. Más que un libro es una atmósfera, Omar Gasca uno de los miembros del Colectivo dice sobre Ulises I

"Si pensamos en los beneficios sociales, es decir en el bien que se hace o se recibe, en una suerte de utilidad o provecho, el proyecto del nanosatélite Ulises tiene varios:

El primero, en cuanto para el ámbito social constituye un ejemplo de gestión de un nivel muy complejo que indirectamente sostiene -y pretende contagiar la idea- de que con esfuerzo se pueden llevar adelante iniciativas o proyectos y ocuparse de la conceptualización, administración, organización y ejecución, aun tratándose de un proyecto tan raro y desacostumbrado. 
En segundo lugar, se trata de un proyecto colectivo que entre otras cosas expresa a la sociedad con claridad que la unión hace la fuerza, esto es que la cohesión o el acto de reunirse y adherirse permite alcanzar objetivos y metas cuya dificultad parecería hacerlas imposibles. El mensaje en éste y en el apartado anterior es: "sí se puede", concepto que no por su simplicidad es menos valioso, especialmente cuando diversos sectores sociales acusan cierto desánimo de cara al futuro.

El tercer caso es una declaración abierta vinculada con los límites y refiere a la idea de la ciudadanización del espacio: no se necesita ser una agencia espacial de ningún país para "ocupar" un segmento del mismo. Un cuarto beneficio lo representa el hecho de que podemos hallar que el proyecto abre también un nicho de oportunidad a los artistas: hay más espacios donde actuar.

Por último, las ideas de gestión, de cohesión y la ciudadanización del espacio se inscriben en la lógica de las previsiones sociales para el futuro, pues a relativo corto plazo no sólo la investigación, la indagación, la exploración del espacio harán su materia de él sino que tocará al individuo social y a los colectivos sociales hacerse de él o al menos de una parte. "

McLuhan y Duchamp, para variar, desde 1964, en diversas plataformas del quehacer humano hemos venido comprobando que "el medio es el mensaje". El aforismo de McLuhan, ahora como parte de la línea argumental del Ulises I, se expresa en la idea de que proyecto y tecnología funcionan como prótesis del concepto. Si, además, como decía Duchamp , "el objeto del arte no es el objeto del arte, es sólo el centro de la discusión”, el orden de los factores conduce reflexionar. Ulises I es, entre otras cosas, un dispositivo para pensar sobre las relaciones entre el medio y el mensaje. Reclama el sentido de lo imaginario, la necesidad de imaginación. Es una referencia a Julio Verne y como es que su literatura generó el imaginario para impulsar la exploración del siglo pasado. Sus mapas, personajes, invenciones le dieron a la exploración su sentido y su contexto. Urge imaginación, sobra tecnología.

El pasado diciembre del 2017 el Colectivo Espacial Mexicano se constituyó legalmente en una agencia espacial civil en México creada por artistas.

Aqui algunas ilustraciones de nuestras actividades.

Misiones Ulises 1 y 2, Diciembre , 2015. 
Ulises I, lanzamiento poético a la estratósfera desde la Feria Internacional del Libro de Guadalajara,lanzamiento por el Colectivo Espacial Mexicano, en colaboración con el Instituto de Astrofísica Óptica y Electrónica y la Feria Internacional del Libro.

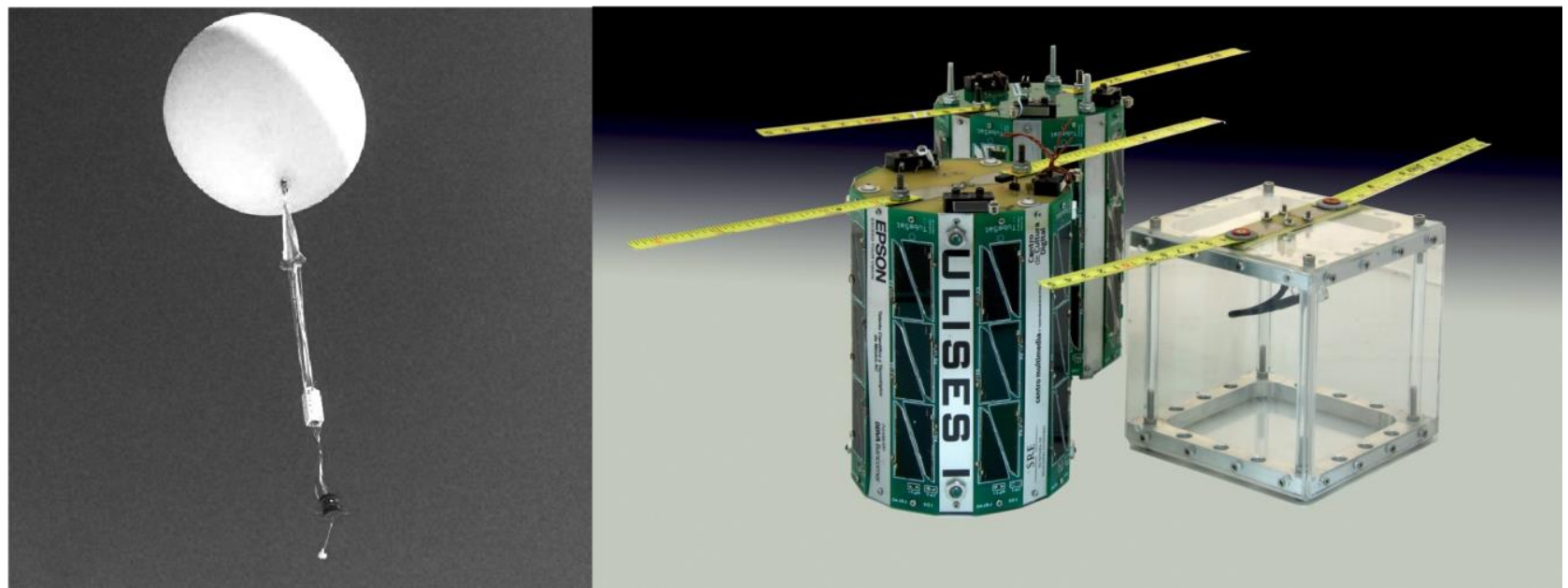

Ulises 2 Lanzamiento fotográfico a la estratósfera por la UNAM.

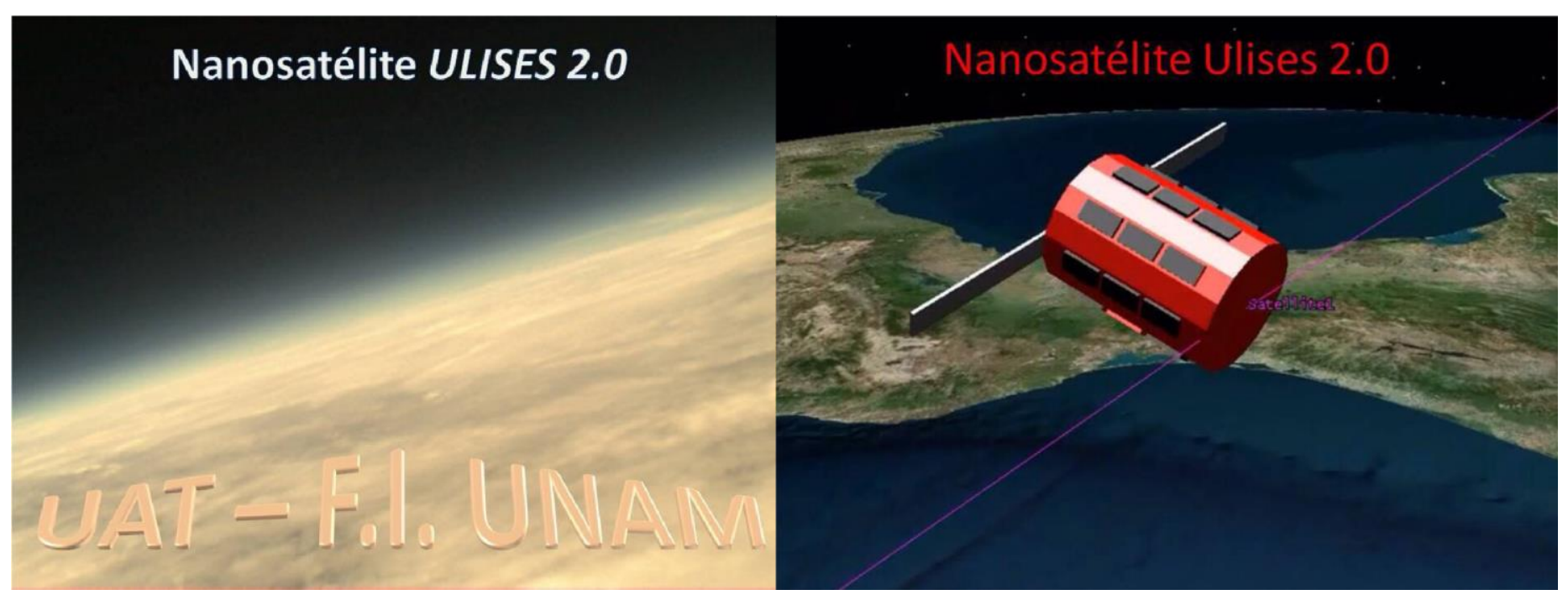

Después de la edición del libro. Otros eventos paralelos

Diseño de naves

Barragan 1, foldable structures diseño del Colectivo Espacial Mexicano.2017 Ulises 4, cubesat misión. 

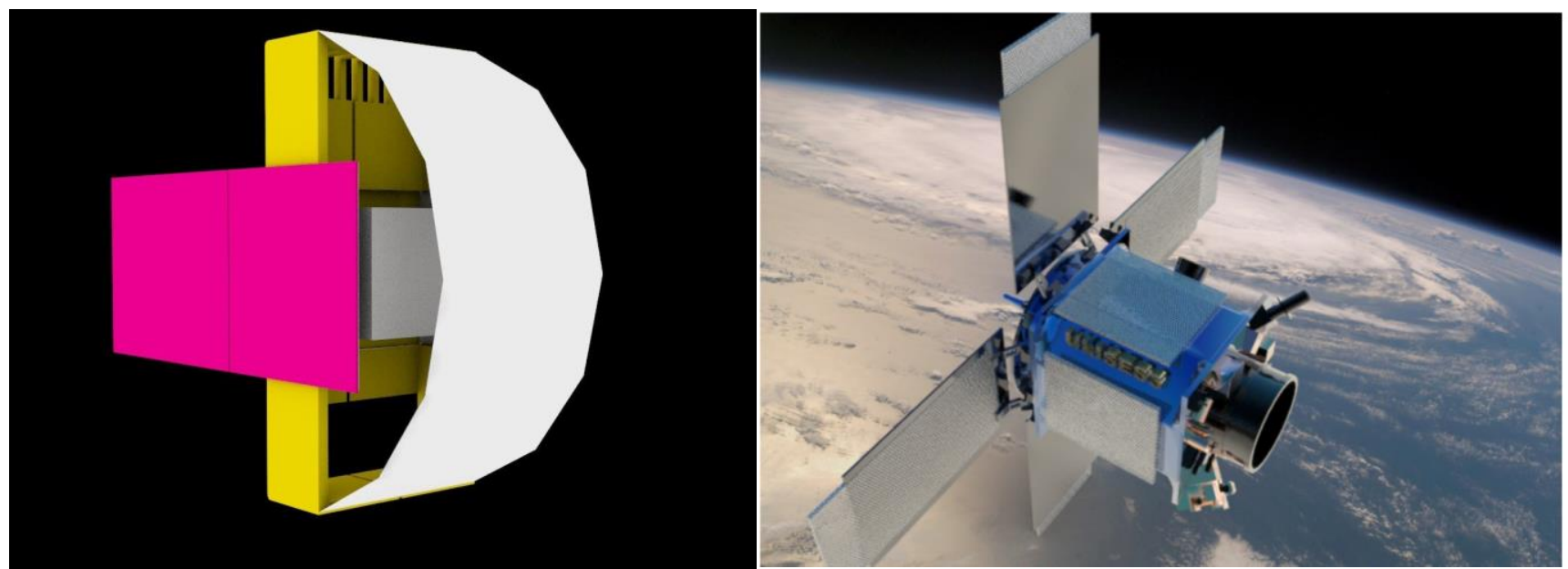

Fabrica, (Beneton) 2018, Treviso Italy. Workshops on cansats para festival "high on subversion"

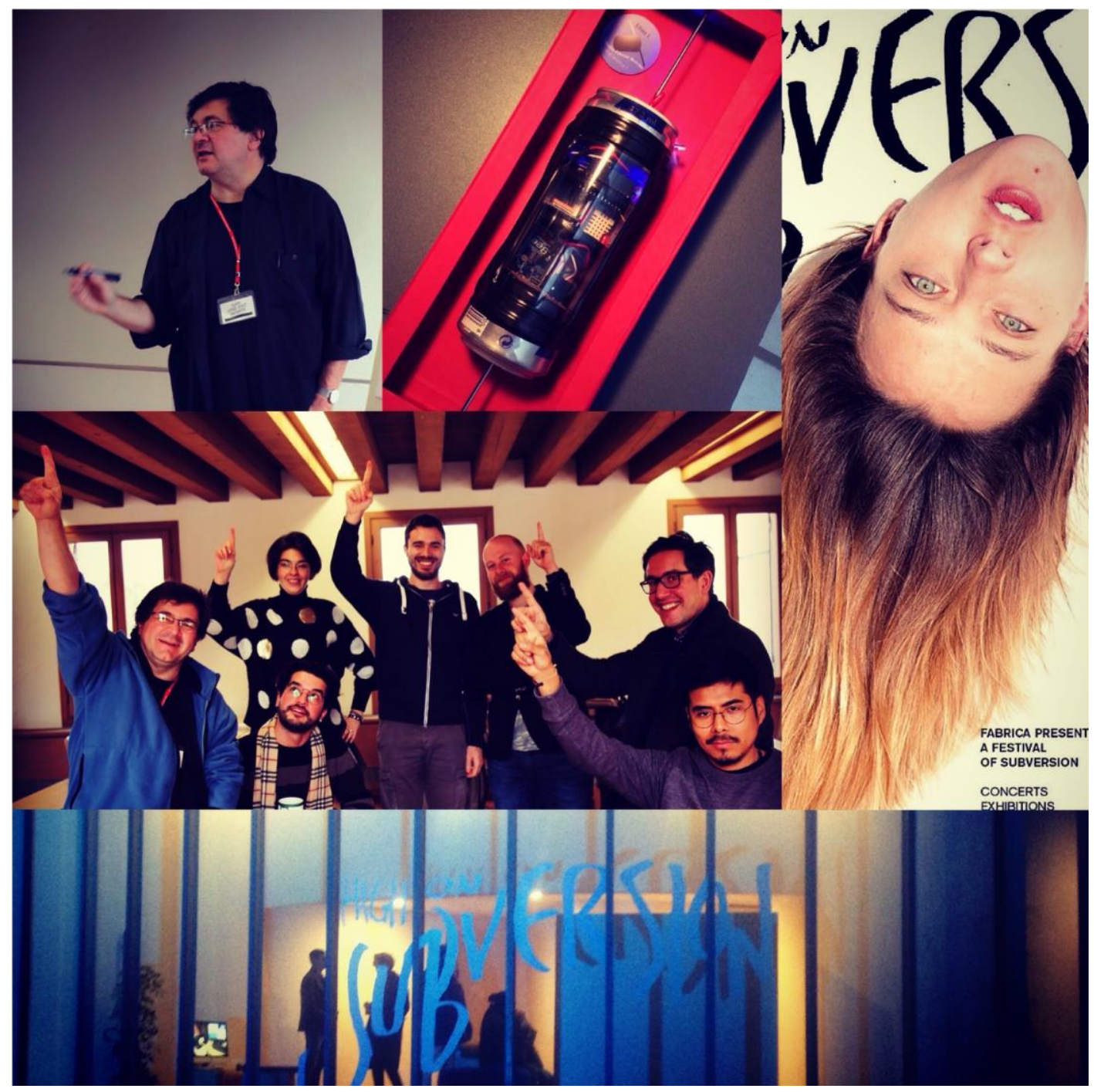

Curaduría y gestión, Claudio Maccone, SETI, "El lenguaje de los extraterrestres" 2017 
Conferencia sobre un algoritmo matemático para establecer un diferencial de cultura en un probable encuentro extraterrestre. FIL de Guadalajara 2017.

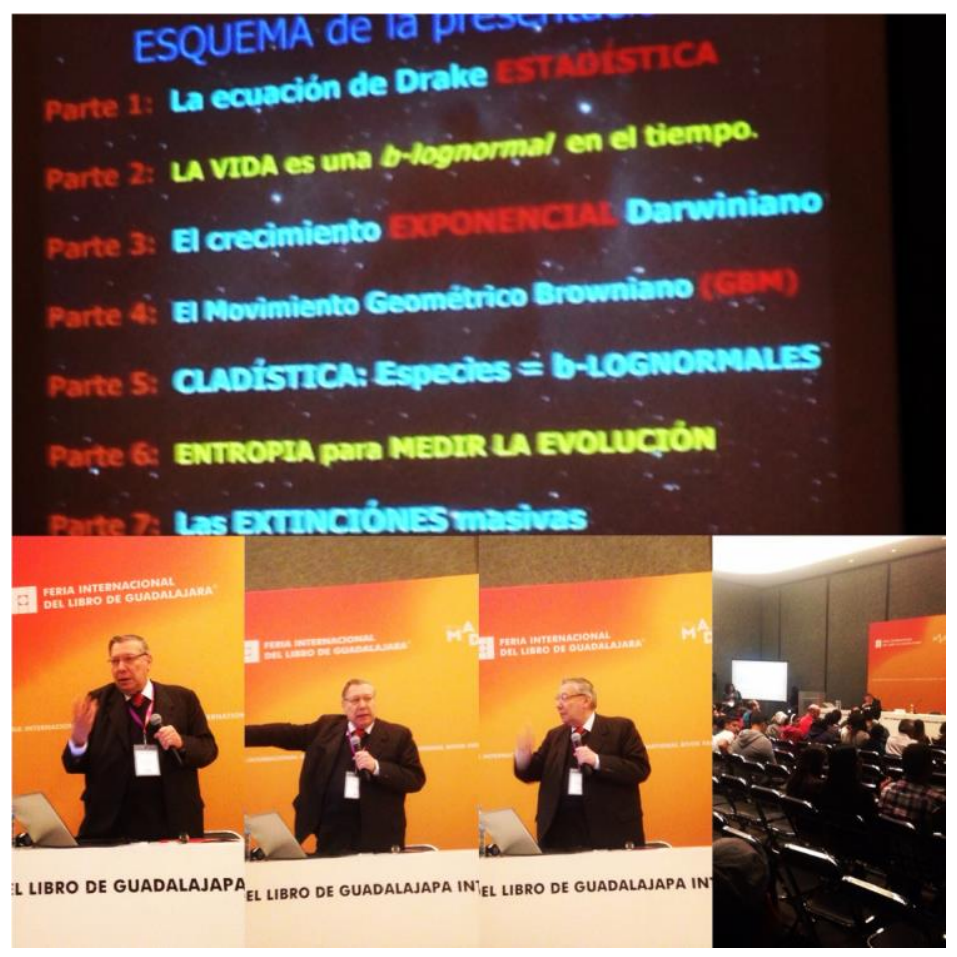

Moonbounce del Quijote, Transmisión del Quijote la Luna, 2016 
DasQuestões,n\#6, setembro/dezembro, 2018 